\title{
Research On Motion Character of the Parallel Precision Piston Pump
}

\author{
Bin Liu ${ }^{1, a,}$, Mingfu Yin ${ }^{1, b, *}$ and Tianshi Zhou ${ }^{1, c}$ \\ ${ }^{1}$ School of Mechanical Engineering, Tianjin Polytechnic University, Tianjin 300387, China \\ abinliu_tj@126.com, byinmingfu@163.com, c18632616175@163.com \\ *corresponding author: Mingfu Yin
}

Keywords: Piston Pump, Motion Character, non-uniformity of displacement.

\begin{abstract}
Control precious of flow by swash-plate inclination is the only way of traditional axial piston pump flow control. Firstly, this paper introduces a design of parallel precision piston pump that drived by AC servo motor. This paper work out the correlation between flow and law of motion. At the same time, paper conducts the positive relationship between non-uniformity of displacement and control accuracy of the system, the inversely proportional relationship between non-uniformity of displacement and length of stroke. Paper provides theoretical foundation for constant flow output and the design of control system.
\end{abstract}

\section{Introduction}

Piston pump was widespread applied in the field as oil, chemical and medicine industry. It has the advantage as high rated pressure, compact structure and simple to adjust flow. Special for the field that need high pressure and accurate flow, piston pump hold the obviously advantage than other type pump [1]. By inclination of swash-plate control was the only way for the flow control of swash-plate axial piston pump which the most common ones on the market [2]. Mass and volume of the swash-plate axial piston pump was increased due to its complex structure, its drive system is hard to designed, and its volume is un-constant. Therefore, this paper provide a precision piston pump system consist of two piston pump that dirved by servo motor. This pump system combine the advantage both high pressure of piston pump and constant flow of new structure so that this is a pump could conduct constant flow \& pressure to meet new requirement of market.

\section{Working principle}

\subsection{Single pump structure introduction}

Single pump (as fig.1) was consisted by AC servo motor, harmonic gear reducer, screw rod, screw-nut, piston and pump shell. This structure have some character was improved that control precision, low-frequency characters, torque-frequency characteristic, overload capacity and speed response etc. [3] due to servo motor instead of stepped motor. Rotational motion of motor was switch to linear motion of piston by conversion device (harmonic gear reducer, screw rod, screw-nut), piston was drived to do straight reciprocating motion. 


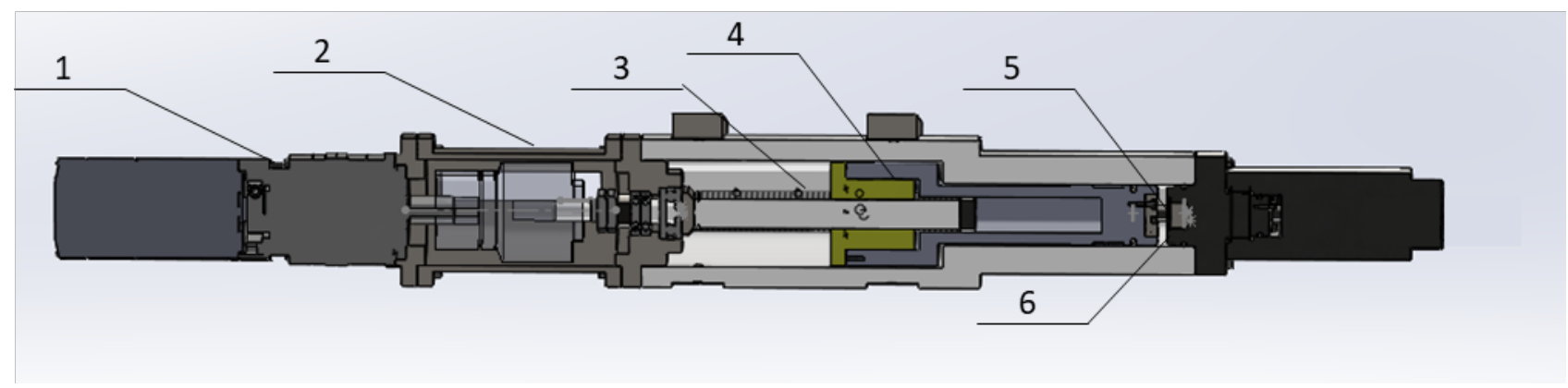

1. Severo motor 2. Harmonic gear reducer 3. Screw rod 4. Screw-nut 5. Piston 6. Pump shell

Fig. 1 Single pump structure

\subsection{Pump system structure}

Pump system (as fig.2) is consisted by 2 pump which introduced in 2.1 section. Pressure was controlled by pressure transmitter. System flow was controlled by servo motor motion principle. Controller drive the motion principle of 2 pump by control voltage signal of servo motor, consequently, this pump system could conduct constantly pressure and flow fluid.

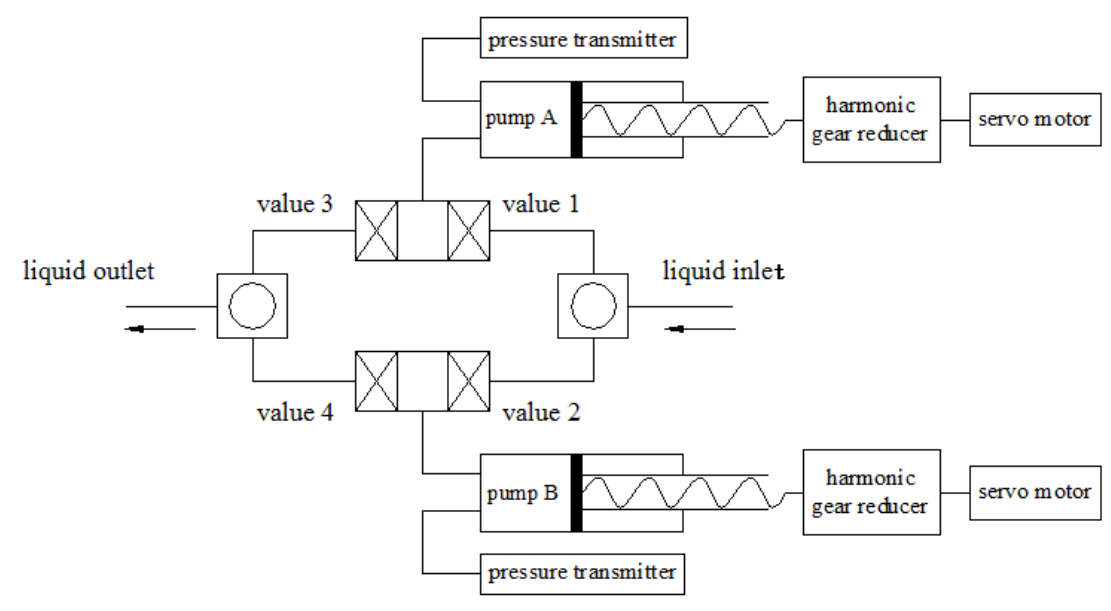

Fig. 2 Parallel pump system structure

\subsection{Piston motion principle}

Single cycle motion principle of this constant flow and constant pressure pump system could be describe as 3 phase that showed as below table 1 .

Table 1 Three Scheme comparing

\begin{tabular}{|c|c|c|c|c|c|c|}
\hline Phase & Pump A & Pump B & Valve1 & Valve2 & Valve3 & Valve4 \\
\hline 1 & Uniform acceleration & Backward & Close & Open & Open & Close \\
\hline 2 & Uniform speed forward & $\begin{array}{c}\text { Aspirate liquid \& } \\
\text { load pressure }\end{array}$ & Close & Close & Open & Close \\
\hline 3 & Uniform deceleration forward & $\begin{array}{c}\text { Uniform } \\
\text { acceleration }\end{array}$ & $\begin{array}{c}\text { Open when } \\
\text { Pump1 } \\
\text { speed = }\end{array}$ & Close & $\begin{array}{c}\text { Close } \\
\text { when } \\
\text { Pump1 } \\
\text { speed }= \\
0\end{array}$ & Open \\
\hline
\end{tabular}


Speed function of two pistons in one cycle as below:

$$
\mathrm{u}_{1}=\left\{\begin{array}{c}
\frac{6 v_{1}}{\mathrm{~T}} t, t \in\left[0, \frac{\mathrm{T}}{6}\right] \\
v_{1}, t \in\left[\frac{\mathrm{T}}{6}, \frac{\mathrm{T}}{2}\right] \\
4 v_{1}-\frac{6 v_{1}}{\mathrm{~T}} t, t \in\left[\frac{\mathrm{T}}{2}, \frac{2 \mathrm{~T}}{3}\right] \\
8 v_{2}-\frac{12 v_{2}}{\mathrm{~T}} t, t \in\left[\frac{2 \mathrm{~T}}{3}, \frac{3 \mathrm{~T}}{4}\right] \\
-v_{2}, t \in\left[\frac{3 \mathrm{~T}}{4}, \frac{11}{12} \mathrm{~T}\right] \\
-12 v_{2}+\frac{12 v_{2}}{\mathrm{~T}} t, t \in\left[\frac{11}{12} \mathrm{~T}, \mathrm{~T}\right]
\end{array} \quad u_{2}=\left\{\begin{array}{c}
v_{1}-\frac{6 v_{1}}{\mathrm{~T}} t, t \in\left[0, \frac{\mathrm{T}}{6}\right] \\
2 v_{2}-\frac{12 v_{2}}{\mathrm{~T}} t, t \in\left[\frac{\mathrm{T}}{6}, \frac{\mathrm{T}}{4}\right] \\
-v_{2}, t \in\left[\frac{\mathrm{T}}{4}, \frac{5}{12} \mathrm{~T}\right] \\
-6 v_{2}+\frac{12 v_{2}}{\mathrm{~T}} t, t \in\left[\frac{5}{12} \mathrm{~T}, \frac{\mathrm{T}}{2}\right] \\
-3 v_{1}+\frac{6 v_{1}}{\mathrm{~T}} t, t \in\left[\frac{\mathrm{T}}{2}, \frac{2}{3} \mathrm{~T}\right] \\
v_{1}, t \in\left[\frac{2}{3} \mathrm{~T}, \mathrm{~T}\right]
\end{array}\right.\right.
$$

In function (1), $u_{1}, u_{2}$ is instantaneous speed of piston A and B; $v_{1}$ is the max speed when piston discharge fluid; $v_{2}$ is the max speed when piston during backward. It is not difficult to draw the below function according to definition of flow and piston motion principle:

$$
\mathrm{Q}=\sum_{i=1}^{2} A u_{1}=\mathrm{A} v_{1}=\mathrm{C}
$$

In function (2), $Q$ is theoretical flow of pump system, $A$ is sectional area of pump bowl. So, this pump could conduct constant flow fluid when operate as stated as this section.

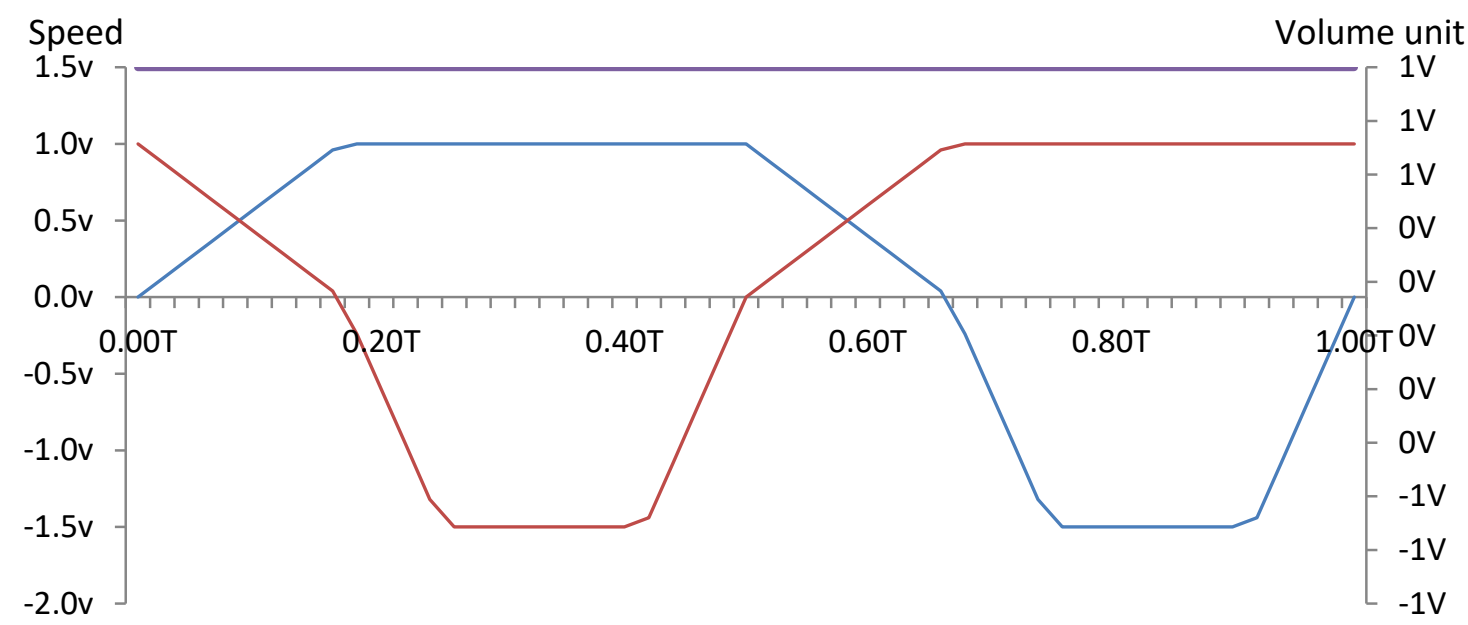

Movement characters of pump A — Movement characters of pump B — System flow

Fig. 3 Pump motion and system flow curve

\section{The influence for system flow analysis that was caused by piston phase difference}

Two pump of this system have same motion principle. Phase difference of two pumps is T/2 in order to conduct constant flow. The phase difference is controlled by control system. Phase error will never be elimination due to control system was influenced by control accuracy. So, actual flow of this system will have deviation and fluctuation. As Fig.4, set pump A phase as baseline, assume phase difference is $t_{q}$, Pump B motion principle as: 


$$
u_{2}^{\prime}=\left\{\begin{array}{c}
v_{1}-\frac{6 v_{1}}{\mathrm{~T}}\left(\mathrm{t}-t_{q}\right), \mathrm{t} \in\left[t_{q}, \frac{\mathrm{T}}{6}+t_{q}\right] \\
2 v_{2}-\frac{12 v_{2}}{\mathrm{~T}}\left(\mathrm{t}-t_{q}\right), t \in\left[\frac{\mathrm{T}}{6}+t_{q}, \frac{\mathrm{T}}{4}+t_{q}\right] \\
-v_{2}, t \in\left[\frac{\mathrm{T}}{4}+t_{q}, \frac{5 \mathrm{~T}}{12}+t_{q}\right] \\
-6 v_{2}+\frac{12 v_{2}}{\mathrm{~T}}\left(\mathrm{t}-t_{q}\right), t \in\left[\frac{5 \mathrm{~T}}{12}+t_{q}, \frac{\mathrm{T}}{2}+t_{q}\right] \\
-3 v_{1}+\frac{6 v_{1}}{\mathrm{~T}}\left(\mathrm{t}-t_{q}\right), t \in\left[\frac{\mathrm{T}}{2}+t_{q}, \frac{2}{3} \mathrm{~T}+t_{q}\right] \\
v_{1}, t \in\left[\frac{2}{3} \mathrm{~T}+t_{q}, \mathrm{~T}+t_{q}\right]
\end{array}\right.
$$

It $s$ not hard to see that maximum flow of system is $Q_{\max }=A v_{1}$. System flow fluctuation was occurred in the time that two pump discharge fluid in same time. Minimum flow is $Q_{\min }=A v_{1}-$ $\frac{6 v_{1}}{\mathrm{~T}} A t_{q}$. So, non-uniformity of displacement of this pump system is $\delta=\frac{Q_{\max }-Q_{\min }}{Q_{\mathrm{th}}}=\frac{6 t_{q}}{\mathrm{~T}}$. In this function, $\delta$ means non-uniformity of displacement, $\mathrm{Q}_{\text {th }}$ means theoretical average flow.

Assume length of stroke is $\mathrm{S}$, system control accuracy is $\Delta$, we can conduct the conclusion that $t_{c}=\frac{\mathrm{T}}{24} \sqrt{\frac{\Delta}{S}}$ by function (1), in this function, $t_{c}$ means phase difference of pump A. Assume control accuracy is equally, $t_{c}=t_{q}$. So, non-uniformity of displacement of this pump system could be converted to $\delta=\frac{3}{4} \sqrt{\frac{\Delta}{S}}$

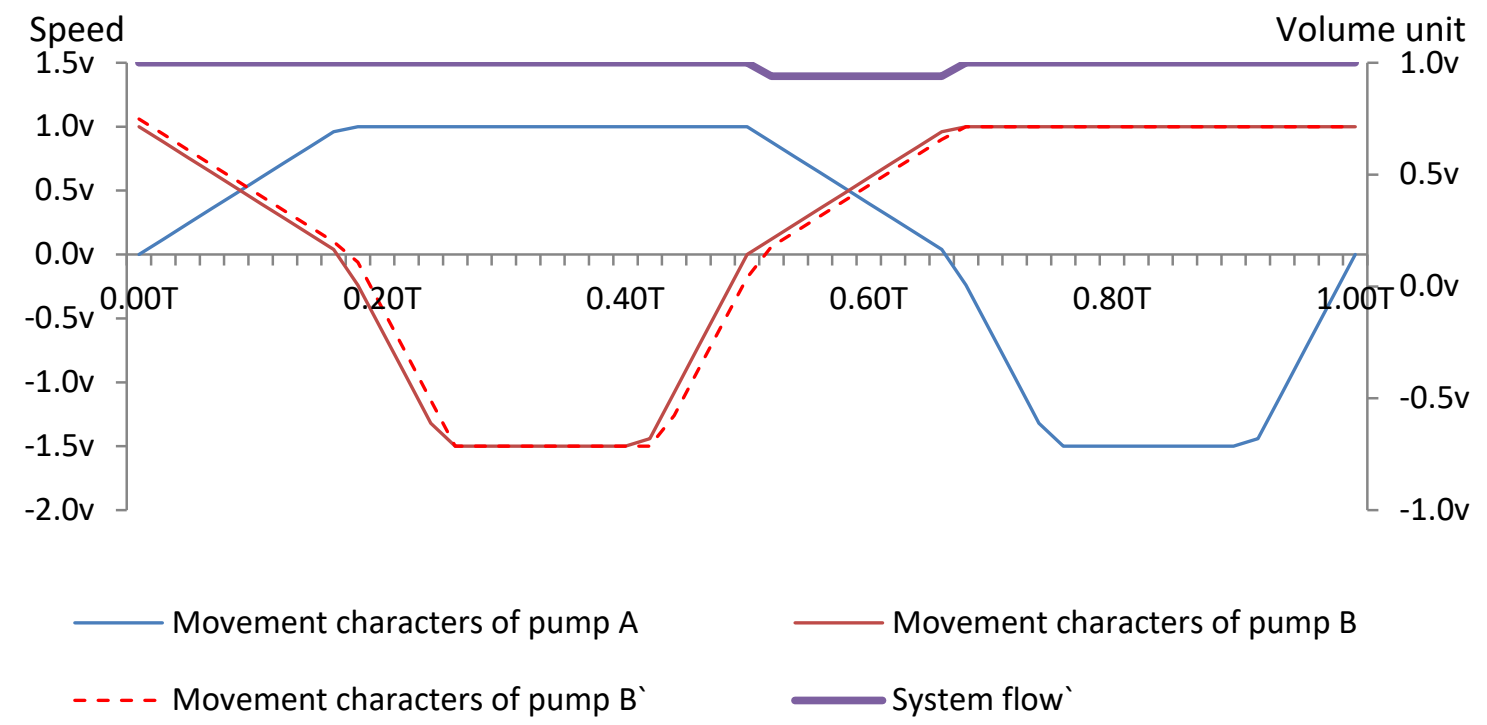

Fig. 4 System flow curve when phase difference is $0.01 \mathrm{~T}$

\section{Conclusions}

1) Compare with traditional swash-plate axial piston pump, this paper provide an new piston pump design which get advantage that simpler structure, constant flow, high pressure, and easy to design. This pump system reflects the trend that digitalizes and minimize.

2) This pump system could achieve constant flow discharge thru analysis

3) Phase difference of 2 pump pistons will take effort to pump system flow, non-uniformity of displacement of this pump system will be more when relative phase difference is more.

4) System control is more accuracy, length of stroke is longer, non-uniformity of displacement is smaller, and flow of pump system will be more stable. 


\section{References}

[1]Guangfei Zhao, Investigation on constant flow axial piston [D]. Taiyuan University of Technology, 2016

[2] ZHANG Chang-ying, Structural Optimization and Process Improvement of Swash-plate Piston Pump for Coal Mine [J]. Coal Mine Machinery 2012,33(11):178-180.

[3] SHI Wen-hong, Research on driving control system of AC motors [J]. Opencast Mining Technology, 2010, (z1):50-51,54.DOI:10.3969/j.issn.1671-9816.2010.z1.022. 